\title{
Ensino de literatura e alunos surdos: diálogo necessário
}

Mirian Theyla Ribeiro Garcia ${ }^{1}$

Resumo: As reflexões desenvolvidas neste artigo estão baseadas no entendimento do letramento literário (uma das dimensões de ensino que se busca ofertar pelo ensino de literatura nas escolas) como um instrumento de suporte considerável para a ampliação do repertório de aprendizagens objetivas e sensíveis dos estudantes. Em vista de sua importância, defende-se que o letramento literário faça parte da formação escolar de todos os alunos. No entanto, o exame da realidade demonstra que há destacado afastamento entre os alunos que possuem Necessidades Educativas Especiais (NEE), a exemplo dos surdos, e essa formação. Em vista disso, argumenta-se sobre a pertinência do desenvolvimento de práticas de letramento literário mais inclusivas nas aulas de literatura.

Palavras-chave: Ensino de literatura. Surdos. Letramento literário inclusivo.

\section{Literature teaching and deaf students: necessary dialogue}

Abstract: The reflections developed in this paper are based on the understanding of literary literacy (one of the many dimensions presented in teaching of Literature in school education) as a considerable support instrument for broadening the repertoire of students' objective and sensitive learning. On account of its importance, it is argued that literary literacy should be part of the school education of all people. However, the examination of reality shows that there is a strong gap between students with disabilities, like deaf for example, and this field of study. For this reason, it is argued about the relevance of developing more inclusive literary literacy practices in Literature classes.

Keywords: Literature teaching. Deaf students. Inclusive literary literacy.

\section{INTRODUÇÃO}

As reflexões desenvolvidas neste artigo estão baseadas no entendimento do letramento literário como uma dimensão prática de articulação entre a literatura e a educação. Em virtude desta vinculação, pode-se afirmar que o letramento literário é um instrumento de suporte considerável para a ampliação do repertório de aprendizagens objetivas e sensíveis dos estudantes.

Em vista de sua amplitude e relevância para o aprimoramento escolar e humanístico, defende-se que o letramento literário faça parte da formação escolar de todos os alunos. No entanto, o exame da realidade das escolas demonstra que esse coletivo de competências não tem sido desenvolvido de forma eficaz nas escolas de todo o país. Como resultante deste cenário, cada vez

\footnotetext{
${ }^{1}$ Professora de Língua Portuguesa da Secretaria de Estado de Educação do Distrito Federal (SEDF). Doutora em Literatura e práticas sociais pela Universidade de Brasília $(\mathrm{UnB})$ com pesquisa que aborda questões sobre o ensino de literatura a alunos surdos matriculados em turmas inclusiva inclusivas regulares. E-mail: mtheyla@gmail.com.
} 


\section{MTIFAR REFLETIONIS}

Revista Eletrônica de Graduação e Pós-Graduação em Educaçāo

menos alunos têm desenvolvido o hábito e o gosto pela leitura literária. Esse afastamento, por diferentes razões, representa prejuízo para a formação escolar, notadamente para o desenvolvimento de habilidades de leitura.

No caso dos alunos que possuem Necessidades Educativas Especiais ${ }^{2}$ (NEE), este prejuízo é ainda mais grave. Isso porque tais estudantes sofrem tanto com os problemas gerais do ensino de literatura quanto com os de caráter mais específico, como o de seu afastamento das práticas de leitura literária em função de presumidas limitações de suas habilidades e competências.

Os problemas relativos às práticas de letramento literário constituem um panorama complexo. Sendo assim, eles não ocorrem desvinculados das questões especificamente relacionadas aos alunos, no entanto, eles também surgem de problemas estruturais relativos ao ensino de literatura e à própria educação em si. Como exemplo destes problemas, cita-se a adoção de processos pedagógicos que, por não estarem orientados para a constituição de sujeitos letrados, propiciam pouco ou nenhum contato com a literatura.

Em vista de sua relevância, entende-se como apropriado e urgente o estudo e o debate sobre o ensino de literatura para todos os alunos, incluídos neste rol, como mencionado anteriormente, os alunos com NEE. Com base neste entendimento, busca-se com este artigo chamar a atenção para o tema do letramento literário em perspectiva inclusiva, estimulando a reflexão e a disposição para o diálogo que devem preceder e acompanhar o desenvolvimento de práticas de ensino mais efetivas e significativas.

\section{ESCOLA E LITERATURA EM CONTEXTO DE DESENVOLVIMENTO DE PRÁTICAS SOCIAIS LETRADAS}

Quando se pensa em encontros entre a literatura e a escola não se pode deixar de situar a importância desta associação para a aquisição e aprimoramento das habilidades e competências linguísticas/discursivas. Isso porque a escola é apontada como "agência de letramento por excelência de nossa sociedade" (KLEIMAN, 2007, p. 4) e espaço privilegiado para o aprimoramento das práticas sociais letradas com seus múltiplos letramentos.

\footnotetext{
${ }^{2}$ Optou-se por utilizar esta nomenclatura por ser ainda a mais comumente utilizada. No entanto, é oportuno referir que há profissionais em educação que preferem empregar a expressão "estudante com Atendimento Educacional Especializado" (AEE) em lugar de "estudante com NEE". Tal opção, de acordo com quem utiliza este registro linguístico, é não estigmatizar, ainda mais, os alunos com especificidades que demandam atendimento pedagógico individualizado.
} 


\section{MTIFRAR REFLECTIONIS}

Revista Eletrônica de Graduação e Pós-Graduação em Educaçāo

Já a literatura, por seu turno e considerada neste mesmo contexto de multiletramentos, também é relevante. Ela promove (entre outras habilidades) o estimulo ao desenvolvimento do senso crítico, da intelectualização, da criatividade e da sensibilidade dos estudantes. Tais competências são essenciais para a inclusão social.

Infelizmente, a parceria entre escola e literatura ainda não tem conseguido reverter um cenário crítico de comprometimento das competências essenciais para a plena inserção em práticas sociais letradas. No caso das escolas, o insucesso é percebido pelo senso comum e pode ser constatado objetivamente. Para tanto, pode-se referir os resultados obtidos em avaliações globalmente aplicadas, a exemplo do PISA (sigla para Programme for International Student Assessment - Programa Internacional de Avaliação de Estudantes).

Os resultados nas avaliações, juntamente com outros índices, oriundos do próprio cotidiano escolar ou resultantes de sua análise, alimentam uma série de reflexões. Entre elas

como alunos de relativamente longa duração de escolaridade puderam desenvolver capacidades leitoras tão limitadas? A que práticas de leitura e propostas de letramento estiveram submetidos por cerca de dez anos? A que textos e gêneros tiveram acesso? Trata-se de ineficácia das propostas? De desinteresse e enfado dos alunos? De ambos? Que fazer para construir letramentos mais compatíveis com a cidadania protagonista? (ROJO, 2009, p. 35)

Efetivamente, são muitas as dúvidas e, diante da gravidade e multidimensionalidade do tema, diversos são os caminhos possíveis para a reversão do quadro de dificuldade enfrentado pelas escolas em suas ações pedagógicas em prol da leitura. Em comum, as propostas baseiam-se na defesa do fortalecimento da interconexão entre as práticas de alfabetização e os mais diversos tipos de letramentos como estratégia para assegurar a formação de alunos que sejam leitores competentes, isto é, capazes de compreender - e não apenas decodificar, o que leem. Entre tais letramentos, reitera-se a pertinência do letramento literário.

\section{LETRAMENTO LITERÁRIO: COMPETÊNCIA AMEAÇADA}

O letramento literário é largamente referido como propício para o aprimoramento da competência leitora. Mas seu aproveitamento não se restringe a tal uso. Destarte, o letramento literário pode ser entendido como um instrumento de suporte considerável tanto para a ampliação do repertório de aprendizagens objetivas (como no caso específico da competência leitora) quanto sensíveis dos estudantes. Em função de tal amplitude, defende-se que essa prática faça parte da 


\section{IrTeparius REFLECTIONIS}

Revista Eletrônica de Graduação e Pós-Graduação em Educaçāo

formação escolar de todos os alunos, articulando benefícios em frentes importantes e que, de maneira geral, permanecem desconexas.

Como resultado óbvio de tal desconexão, nas escolas — ambientes responsáveis pela criação e o fortalecimento das habilidades de leitura e escrita (sem as quais, o(s) letramento(s) não ocorre(m); os alunos que de fato possuem habilidades consolidadas de leitura e contato aprofundado com a literatura são, comparativamente, a minoria. Paralelamente, o quantitativo de estudantes para os quais a leitura literária representa não mais que uma mera obrigação é considerável.

Este quadro de dificuldade das práticas de ensino de literatura/letramento literário enfrentado nas escolas representa uma desvantagem inapelável à formação oferecida aos indivíduos. Isso porque ele frustra o projeto de oferta da educação comprometida com o pleno desenvolvimento das pessoas como maneira de prepará-las tão apropriadamente quanto possível para o exercício da cidadania.

Neste caso, em consonância com o que está proposto nas Orientações Curriculares Nacionais para o Ensino Médio (BRASIL, 2008, p. 55), entende-se como "necessário e urgente" reconsiderar o letramento literário em contexto escolar. Tal reexame deve, entre outros aspectos, incentivar a perspectiva da experiência literária enquanto fomentadora da construção do conhecimento em variados campos.

Em função de sua gravidade, as deficiências encontradas no ensino de literatura em todo o país deveriam estimular amplo debate para enfrentamento desta situação de insucesso instaurada no campo educacional. No entanto, isso não acontece como deveria. Assim, embora se reconheça que os currículos escolares estejam sendo debatidos e revisados e que nas áreas de linguagens em geral observem-se avanços consideráveis, ainda há muito a aprimorar. Isso porque as questões relativas ao ensino de literatura ainda constituem conteúdo insuficientemente estudado (BISPO; JÚNIOR, 2016) ou restrito à dimensão teórica, sem aplicação prática evidente (SEGABINAZI; SILVA, 2015).

Desta maneira, embora exista um discurso que evidencie a preocupação e defesa da leitura e estudo de literatura na escola enquanto prática de relevância inconteste em variados aspectos, os debates e reflexões a respeito deste tema são, ainda, incipientes. Consequentemente, destaca-se que "o contexto de ensino de literatura no Brasil parece não ter acompanhado as mudanças ocorridas nos diversos âmbitos sociais, assim como na área de produção de conhecimento.” (NASCIMENTO, 2013, p. 200). 


\section{MTIFRAR REFLETIONIS}

Revista Eletrônica de Graduação e Pós-Graduação em Educaçāo

Sem o necessário debate e atualização frente aos novos desafios e paradigmas inerentes à educação e à vida em sociedades complexas, a educação literária encontra-se, em diversos aspectos, estagnada. Em razão de tal inércia, não causa espanto que o estudo de literatura nas escolas venha sendo gradativamente percebido como elemento pedagógico "supérfluo", "que serve apenas para distrair." (FREDERICO; OSAKABE, 2004, p. 72).

O processo de desprestígio referido está associado a outro, que o precede e consolida: a concepção problemática que atualmente se tem sobre a própria literatura. Como resultado mais evidente de tal dinâmica observa-se que nas aulas desta disciplina há de tudo, "menos literatura de fato" (SEGABINAZI; SILVA, 2015, p. 68). Isso ocorre porque, em uma clara tentativa de tentar transformar esse conteúdo em algo “útill” à formação dos alunos, conteúdos de natureza técnica têm ditado o tom desta disciplina.

Perspectivas como essa deixam claro que a literatura, em âmbito escolar ou universitário, é uma “disciplina ameaçada” (PERRONE-MOISÉS, 2005, p. 27) ou cuja integridade encontra-se vulnerável a interferências de diversas ordens. Essa ameaça permanecerá enquanto não houver renovação dos preceitos teóricos e das práticas cotidianas do ensino de literatura (SEGABINAZI; SILVA, 2015).

A predominância de métodos de ensino prescritivos desvincula a literatura do mundo do qual ela faz parte, tornando-a estéril. Neste caso, a despeito da abrangência conceitual desta linguagem incluir uma evidente dimensão educativa, seu alcance se torna restrito. Esse tipo de a distorção seria suscitada pelo que TODOROV (2009) define como uma concepção estreita do que, de fato, seja literatura.

O entendimento limitado das potencialidades da literatura é um dos grandes responsáveis pela proposição e prática de métodos de ensino (ou "escolarização da literatura") que são rejeitados por críticos literários, teóricos da educação, professores e alunos. A resistência ocorre, sobretudo, contra a planificação dos conteúdos literários com vistas à inserção em grades curriculares de ensino de literatura que ainda seguem modelos convencionais e quase que inalterados desde sua origem. Inseridos em contextos desta natureza, a leitura e o estudo de textos literários são empregados tão somente como instrumentos para a memorização de conhecimentos de ordem normativa e sem vinculação com as complexidades da vida fora do ambiente escolar.

Em decorrência desta linha de pensamento utilitarista, há desvalorização da leitura de textos literários, reduzindo o alcance da literatura a uma "função patrimonial". Essa função, de 


\section{MTIFAR REFLECTIONIS}

Revista Eletrônica de Graduação e Pós-Graduação em Educaçāo

acordo com COLOMER (2007, p. 37), circunscreve os estudos literários à exemplificação de extensas listas de datas, estilos de época, nomes de autores e títulos de obras.

Nesse cenário, independentemente da reconfiguração imposta pelas atuais necessidades de habilidades de leitura e escrita dos estudantes, os textos literários são entendidos superficialmente. Isso faz com que estas produções sejam utilizadas como suporte (ou "pretexto") para, por exemplo, apenas subsidiar o ensino de gramática ou de história da literatura.

Um dos principais problemas com este tipo de método de ensino, além da óbvia falta de elementos que evidenciam a relevância da literatura para a vida, é que eles, a qualquer momento, podem abdicar da utilização (ainda que fragmentada) dos textos literários. Isso pode acontecer porque não há compromisso com a formação abrangente dos alunos, mas apenas com a leitura, mesmo que vertiginosa e esquizofrênica, do maior quantitativo de exemplos de gêneros textuais.

Nesse contexto, conforme aponta DIAS (2016), há uma tendência das instituições de ensino em apresentar a literatura como uma disciplina em estado de prontidão defensiva permanente. Tal posição de alerta surgiria como uma resposta antecipada às constantes ameaças a esse conteúdo. Entre elas o "gerenciamento" de temas considerados inapropriados — sobretudo aos leitores infantis; e à preponderância de estudos de características técnicas dos textos literários.

Mas há outro ponto crítico referente ao ensino de literatura prescritivo e enciclopédico. Ao focar-se no caráter utilitário da leitura, não se permite ao aluno apropriar-se de maneira plena e livre do texto literário, cerceando as possibilidades de elaboração de significados de seus processos de leitura. Quando isso acontece, a leitura fica comprometida, restringindo o alcance da experiência literária, isto é, das complexas relações estabelecidas a partir do contato com a dimensão textual da obra e que a ultrapassam.

Esse cenário, ainda de acordo com DIAS (op. cit., loc. cit.), mais afasta que aproxima o estudante da literatura. Isso ocorre porque o estudo desta disciplina tendo em vista a análise predominantemente formal e técnica não constitui a única (e nem a mais instigante) via possível para apreensão da experiência literária. A rigor, a insistência nesse tipo de abordagem "dificilmente poderá ter como consequência o amor pela literatura." (TODOROV, 2009, p. 33).

No entanto, na contramão do que é proposto por Todorov, a vinculação afetiva com a literatura é aspecto que costuma ser desconsiderado nas escolas que, impelidas pelo rigor do saber científico, encontram-se mais focadas na hierarquização e linearidade lógicas na construção do conhecimento. Esta perspectiva, no entanto, é controvertida porque ignora que a afetividade é, também, um processo importante para a formação global do ser humano. Sua relevância está 


\section{MTIFAR REFLECTIONIS}

Revista Eletrônica de Graduação e Pós-Graduação em Educaçāo

associada, sobretudo, ao seu potencial de estimulação da criatividade, da sensibilidade, da imaginação e ao exercício da liberdade (de expressão, de pensamento, de sentimento etc.).

Como resultante desta e de outras concepções que podem restringir a experiência literária, observa-se que o ensino de literatura tem sido marcado por graves comprometimentos. Esses, por sua vez, contribuem para o afastamento dos alunos de um campo do saber que, "seja em nome da ordem, da liberdade ou do prazer" (COSSON, 2012, p. 25), é ensinado como elemento capaz de "garantir a função essencial de reconstruir a palavra que nos humaniza" (op. cit., loc. cit.).

O prejuízo que advém da adoção de práticas pedagógicas meramente procedimentais, quer seja para alunos com NEE ou não, é inequívoco. Isso porque, dependendo da abordagem, o estudo de literatura pode ser bastante profícuo ou o seu oposto, não contribuindo nem para a construção do conhecimento técnico e nem para o aprimoramento sensível (ZILBERMAN e SILVA, 2008, p. 43).

\section{LETRAMENTO LITERÁRIO E ENSINO INCLUSIVO: POTENCIALIDADES E DESAFIOS}

A discussão sobre os modos como a literatura enquanto disciplina escolar é expressa e desenvolvida nas escolas envolve ainda uma questão. Trata-se do tema do letramento literário não formal, conceito importante para a reflexão a respeito das práticas de letramento literário, sobretudo as que possuam orientação mais inclusiva.

Para compreender esse conceito, convém reforçar a concepção restritiva que caracteriza o modo como o letramento literário ainda é desenvolvido em grande parte das escolas brasileiras. Nesses ambientes predomina o entendimento segundo o qual o estudo de literatura deve estar focado, necessariamente, na memorização de características como padrões do gênero literário, elementos de estilo, contextos históricos e dados sobre a vida e obra de autores considerados representativos.

Esse tipo específico de abordagem do ensino de literatura, embora justificável para muitos, não é o único possível, sobretudo quando se pensa o ensino de literatura voltado ao diálogo com as vivências e leituras pessoais dos alunos. No entanto, a existência (e permanência) de métodos tão convencionais de ensino de literatura evidenciam "que há um letramento literário escolar formal, regido por normas e convenções de leitura e há outro letramento literário, o social" (ZAPPONE; YAMAKAWA, 2013, p. 187). 
As práticas de leitura informais, ou não chanceladas pela escola estariam inseridas em um modelo de letramento conhecido como "autônomo". Este modelo está pautado no reconhecimento da existência e funcionalidade de práticas de leitura literária que ocorrem em contextos mais informais. Diametralmente, nas escolas e em outros ambientes nos quais se privilegia a configuração mais técnica/específica da produção escrita, obras consideradas menos relevantes são sumariamente desconsideradas, ainda que façam parte do cotidiano dos estudantes.

Em contextos como estes, orientados por uma perspectiva excludente de valorização literária, obras não vinculadas ao cânone da tradição letrada não são consideradas e, não raro, sua leitura é desestimulada. Entre estas obras, citam-se as de literatura estrangeira, as pertencentes ao gênero infanto-juvenil, textos de autoria não consagrada (a exemplo dos existentes em blogs) e, também, os títulos (ainda) referidos como "literatura de massa".

Embora ignoradas pela escola, obras pertencentes às categorias citadas são conhecidas e lidas pelos estudantes e surgem como resultado de suas escolhas e expectativas pessoais, não se vinculando, necessariamente, ao rol de títulos e autores apresentados em sala de aula. Tais práticas de leitura, no entanto, são consideradas menos importantes porque as práticas de leitura e letramento comumente defendidas e praticadas nas escolas possuem natureza teórica muito pormenorizada e, por vezes, muito distante do arcabouço de conhecimentos e vivências pessoais dos estudantes (cf. ZAPPONE; YAMAKAWA, 2013).

As práticas de letramento de natureza social (ou não formais) não se constituem por acaso. A rigor, elas parecem resultar, justamente, de ambientes pouco estimulantes de leitura. Assim, é possível entender sua ocorrência como alternativa aos excessos de rigor e tecnicismo normalmente presentes em aulas de literatura. Nessas aulas, com frequência indesejada, impera uma tensa relação na qual instituem-se polarizações e choques entre diferentes práticas de letramentos: as que os alunos já dominam e as que se pretende que dominem.

É importante destacar, quando se pensa em letramento social e o formal, a evidente lacuna que se instala em termos de formação escolar. Neste caso, é importante ter em mente que a mera desconsideração das práticas de leitura não canônicas em detrimento de produções mais convencionais e prestigiadas não permite que haja aproveitamento pedagógico de nenhuma delas efetivamente (op. cit., p. 197).

A análise desse cenário permite perceber que, em muitos casos, as limitações da educação literária na escola estão mais associadas às concepções teóricas e aos métodos de ensino 
adotados do que à natureza do contato com a literatura em si. De outra maneira, os estudantes rejeitariam qualquer tipo de leitura literária, não apenas aquelas desenvolvidas em sala de aula.

Dito isso, entende-se como necessário o compromisso com o estudo e debate de temas pedagógicos problemáticos e com a renovação das abordagens metodológicas. Isso envolve o resgate das razões que fazem do ensino de literatura elemento fundamental à formação integral dos estudantes e conteúdo de relevância permanentemente atualizada frente aos dilemas da Educação. Notadamente no que diz respeito ao grande desafio de formar leitores profícuos e cidadãos mais críticos e éticos.

Desta forma - e retomando o que está proposto nas Orientações Curriculares para o Ensino Médio; defende-se que é preciso ter em mente que o estimulo à formação de leitores literários nas escolas deve ser um compromisso permanente em todas as disciplinas. Isso porque "letrar literariamente" (BRASIL, 2008, p. 55) o estudante não significa apenas instrumentalizá-lo para a leitura de obras literárias. Essa formação, por razões já referidas, permite ao aluno apropriarse "daquilo que é seu por direito" (op. cit., loc. cit.): acesso à educação de natureza mais abrangente e de inegável qualidade. Para tanto, são válidos todos os esforços que busquem estimular o contato aprofundado e significativo entre a literatura e os estudantes.

Outro obstáculo a ser considerado para a reflexão quanto ao tema da educação literária nas escolas, com ou sem NEE, refere-se à ausência de "diálogo" mais efetivo entre a educação e a literatura. A interação entre estes dois campos do saber ainda é tímida e esse afastamento pode constituir uma dificuldade a mais no cotidiano profissional de professores de língua portuguesa e seus alunos. Um de seus desdobramentos óbvios é constituir mais um dificultador para as práticas de letramento literário.

Dessa forma, em vista da importância das práticas de leitura para a vida em sociedade e a potencial contribuição da leitura e letramento literários para o aprimoramento escolar, seria oportuno que as relações entre a leitura, a literatura e o ensino fossem apropriadamente alicerçadas por um suporte teórico próprio, coeso e consolidado em todos os campos. Mas isso ainda não acontece e, com muita frequência, os estudos acadêmicos que tematizam a relação entre literatura e ensino normalmente são "deslocados" para o campo da educação e da pedagogia (DIAS, 2016), sem maior contato com as contribuições dos estudos literários.

Isso não quer dizer que não existam pesquisadores que dediquem suas pesquisas à investigação de temas que envolvam simultaneamente a educação e a literatura. O que se objetiva destacar aqui é que, em termos do diálogo teórico entre literatura e educação, ainda há muito o que 


\section{ITIFPARIus REFLECTIONIS}

Revista Eletrônica de Graduação e Pós-Graduação em Educaçāo

ser discutido e aprimorado. Um exemplo evidente disso é, justamente, o caso do ensino de literatura para pessoas com NEE. Como apontado por GARCIA (2019), as pesquisas acadêmicas sobre esse tema e que partam de pesquisadores oriundos do curso de Letras ou vinculados aos programas de pós-graduação em literatura são, ainda, exíguas.

O distanciamento entre a literatura e a educação existente na produção acadêmica pode representar um importante elemento dificultador das práticas de letramento literário junto aos alunos com NEE. Isso porque o conhecimento que a literatura poderia agregar com relação à formação humana, isto é, o lugar que ela poderia ocupar em termos de produção de conhecimento, é comumente substituído por informações extrínsecas aos conteúdos veiculados pelo texto.

Como resultante das falhas nesta dinâmica, certamente decorrem prejuízos aos estudantes, pois "Educação e Literatura constituem duas áreas do saber absolutamente intrincadas" (CUNHA, 2012, p. 772). Neste contexto de incomunicabilidade, o ensino de literatura não consegue efetivar duas importantes funções. A primeira diz respeito à proposição das bases teóricas necessárias para que sejam desenvolvidas ações pedagógicas que possam estimular o estabelecimento de hábitos de leitura mais consolidados. A segunda, altamente vinculada à anterior, envolve o trabalho prático cotidiano focado na consolidação do letramento literário e a na formação de novos leitores.

Em função das falhas presentes nesta associação, manter esforços para (re)aproximar literatura e educação pode ser considerada uma estratégia importante, haja vista que estes dois campos do saber possuem imemorial e íntima ligação. Desta forma, não há argumentos que subsidiem a cisão entre eles. Em vista disso, o que se objetiva aqui é sugerir a reavaliação da predominância de práticas prescritivas e classificatórias no ensino de literatura. Além disso, sugerese a gradual retomada de abordagens mais agregadoras e dialógicas, capazes de "criar ressonância com o leitor em qualquer tempo ou espaço" (CUNHA; BASEIO, 2015, p. 67).

Ante o exposto, destaca-se que o referido caráter dialógico presente na literatura precisa ser ampliado, criando ressonância não apenas entre o leitor e o texto, mas também entre estes e os profissionais a cargo de estimular tal interação. Nestes termos, a colaboração entre os campos literário e educativo é tão apropriada quanto necessária, afinal, não se vislumbra a existência de razões que justifiquem a separação entre estes campos do saber e que não se insiram na questão da divisão, meramente classificativa, entre as ciências.

Como se não fossem suficientemente graves, os problemas relativos à ineficiência das práticas de ensino de literatura e de letramento literário voltados ao estimulo à formação do leitor 


\section{IrTeparius REFLETIONIS}

Revista Eletrônica de Graduação e Pós-Graduação em Educaçāo

envolvem ainda outros desdobramentos. Um deles é o da já referida ineficiência do ensino de literatura para alunos com NEE. Esses alunos costumam experimentar duplo prejuízo, pois sofrem tanto com os problemas gerais do ensino de literatura quanto com os de caráter mais específico, como o de seu afastamento das práticas de leitura literária em função de presumidas limitações de sua competência leitora.

Neste caso em particular, o ensino de literatura, espaço privilegiado para a promoção do letramento literário, deixa de ser um aliado essencial para o processo de inclusão escolar por meio da leitura. Essa desarticulação resulta em prejuízo pedagógico sem precedentes haja vista que o letramento literário é um "instrumento útil, que oferece aos indivíduos com necessidades especiais a possibilidade de formação intelectual, necessária ao desenvolvimento de suas potencialidades" (PEREIRA, 2000, p. 1).

Um exemplo representativo da ineficácia do ensino de literatura em relação a aos alunos com NEE é dos surdos. Estes alunos, conforme apontam Müller (2016) e Apolinário (2005), frequentemente são acusados de serem maus leitores, de não gostarem de ler. Em função destas e de outras concepções equivocadas, os surdos corriqueiramente não são estimulados como deveriam e poderiam no campo da educação literária.

Como buscou-se demonstrar até aqui, muitos são os dificultadores do letramento literário. No entanto, um panorama de dificuldades como o atual não deve ser encarado como um destino forçoso, mas como um desafio a ser superado. Em vista disso, se a escola busca capacitar seus alunos para serem leitores capazes de ler textos das mais diversas conformações e nos mais variados contextos, ela deve persistir em seus esforços. Sobretudo os de propiciar o aprimoramento de habilidades subjetivas que são tão importantes para o enfrentamento e resolução de dilemas e adversidades da vida cotidiana quanto os saberes de ordem prática.

Essa formação demanda a adoção de práticas de letramento literário em perspectiva mais inclusiva que precisam alcançar "todos os sujeitos inseridos no espaço escolar" (FILIPOUSKI, 2005, p. 225), indiscriminadamente. No entanto, no caso específico de alunos com NEE, a exemplo dos surdos, o diálogo com a literatura e suas práticas de ensino é tão importante quanto urgente.

\section{POR UM LETRAMENTO LITERÁRIO MAIS INCLUSIVO}

O presente artigo é proposto tendo em vista a ampliação da discussão a respeito da formação do leitor literário surdo inserido em turmas regulares e inclusivas de ensino. Tal discussão, 


\section{IrTeparius REFLETIONIS}

Revista Eletrônica de Graduação e Pós-Graduação em Educaçāo

como argumentado anteriormente, não pode acontecer descontextualizada dos princípios estruturantes do próprio ensino de literatura. Isso porque a literatura enquanto disciplina escolar não está isenta de, a qualquer tempo, deparar-se com situações que requeiram a reconsideração de seu caráter epistemológico.

Ademais, alerta-se para o fato de que os processos de ensino e aprendizagem dos alunos com NEE são de interesse de trabalhadores em educação em todas as instâncias. Isso porque o coletivo de alunos com o qual esses profissionais precisarão trabalhar inclui pessoas com conformações fisiológicas, origens geográficas, status sociais e subjetividades próprias (dentre outros especificadores) e por vezes não familiares para os professores. Cada uma dessas pessoas possui motivações, ritmo e forma de aprendizagem diferenciadas, o que demanda maior abertura e sensibilidade dos profissionais de ensino.

Em vista disso, observa-se que grande parte do desafio vivenciado pelas práticas de letramento literário para alunos surdos é o mesmo identificado, em larga escala, pela própria educação. Principalmente se a educação for pensada enquanto conjunto de práticas e esforços voltados à inclusão e oferta de ensino de qualidade para os mais diferentes estudantes.

Tal desafio fica ainda mais evidente quando se examina a questão do ensino de literatura para alunos surdos. Isso porque os temas relativos à surdez e às vivências surdas não se circunscrevem apenas à área da educação especial, ficando restritos ao contato e trabalho exclusivo com um grupo específico de profissionais. Portanto, embora os surdos possam ser considerados como uma "minoria" linguística e cultural, isso não quer dizer que a convivência com eles será rara ou ocasional. Os surdos formam um grupo numeroso e atuante em todas as esferas de convivência social. Sendo assim, sua representatividade em termos pedagógicos está inscrita no campo da educação, sem maiores adjetivações, mas com implicações igualmente complexas.

Dito isso, pode-se afirmar que vários os desafios no ensino de literatura para surdos e outros alunos com NEE. Um deles diz respeito à existência entendimentos, práticas e situações que “apagam” a presença dos surdos. Entre elas a ausência de personagens surdos em obras de destaque no mercado editorial brasileiro, a desconsideração da Literatura Surda (campo de expressão cultural que envolve exclusivamente autores e temáticas surdas) no campo dos currículos escolares e a exiguidade de produções acadêmicas que versem sobre aspectos de convergência entre as práticas de letramento literário e os estudantes surdos. Tais eventos constituem silêncios que não raro resultam em silenciamentos da condição surda e que, por esta razão, precisam ser rechaçados. 
Em vista do que foi argumentado e em reconhecimento às contribuições que tais estudos podem perpetrar, defende-se que a educação inclusiva e o ensino de literatura precisam caminhar juntas. Tal articulação, conforme proposto por CANDIDO (1995), pode contribuir não apenas com a formação escolar dos surdos, mas também com o seu aprimoramento humano.

Para tanto, simultaneamente à proposição de métodos de ensino e à utilização de Libras (Língua brasileira de sinais) enquanto suporte permanente de acesso às aulas e aos textos, sugerese o desenvolvimento de ações pedagógicas em todas as disciplinas com vistas ao conhecimento de produções e questões relativas à comunidade surda enquanto minoria linguística, literária e cultural. Tal reconsideração precisa passar, também, pelas aulas de literatura, que podem ser reorientadas de modo a incluir em seu cotidiano ações que se orientem para a prática de letramento literário em perspectiva mais inclusiva.

A proposição de um letramento literário inclusivo não é descabida. Sua pertinência se deve às diversas contribuições que a educação literária pode propiciar. Por meio dela podem ser propostos meios para a promoção do diálogo que, conforme proposto por CANDIDO (op. cit.), possibilita a criação de uma nova consciência. Tal consciência facultaria ao ser humano compreender melhor sua natureza e os meios dos quais faz parte, estimulando a substituição de entendimentos e princípios cristalizados pela interação pacífica e prolífica com seus semelhantes.

Em vista da argumentação desenvolvida, reitera-se que o diálogo do aluno surdo com a literatura precisa constituir-se como prática pedagógica cotidiana. Essa abertura é proposta tendo em vista princípios basilares da própria educação, a exemplo da orientação humanista das ações desenvolvidas, o respeito à pluralidade e à diversidade individual e cultural e a promoção de práticas democráticas e inclusivas

Assim sendo, encerra-se por ora a discussão e reflexões propostas com o desenvolvimento deste artigo. Tal fechamento se ampara, mais uma vez, no entendimento segundo o qual é necessário que a leitura literária e as práticas de letramento literário sejam permanentemente ressignificadas e atualizadas, fornecendo aos estudantes (surdos e não-surdos) formação escolar que articule tanto o conhecimento técnico quanto o aprimoramento sensível.

A articulação entre estas duas dimensões pode contribuir com o aprimoramento cognitivo e subjetivo dos alunos. Dessa forma serão oferecidas a todos os alunos maiores e melhores condições para participar de forma ativa, crítica e dinâmica dos processos e vivências complexas e típicas da vida cotidiana contemporânea. 


\section{Retriparing}

Revista Eletrônica de Graduação e Pós-Graduação em Educação

\section{REFERÊNCIAS}

APOLINÁRIO, Andréa Aléssio. O que os surdos e a literatura têm a dizer? Uma reflexão sobre o ensino na Escola ANAPACIN do Município de Maringá/PR. Dissertação (Mestrado em Estudos Literários). Maringá: Universidade Estadual de Maringá, 2005.

BISPO, Erica Cristina; JÚNIOR, Heleno Álvares Bezerra. Por um novo currículo no ensino de Literatura: fundamentos, leis e caminhos. Abril: Revista do Núcleo de Estudos de Literatura Portuguesa e Africana da Universidade Federal Fluminense (UFF), v. 8, n. 17. Rio de Janeiro, 2016.

BRASIL. Orientações Curriculares para o Ensino Médio: linguagens, códigos e suas tecnologias. Brasília: Ministério da Educação, Secretária de Educação Básica, 2008.

CANDIDO, Antônio. $O$ direito à literatura. In: Vários escritos. 3.ed. São Paulo: Duas Cidades, 1995.

COLOMER, Teresa. Andar entre livros: a leitura literária na escola. Tradução: Laura Sandroni. São Paulo: Global, 2007.

COSSON, Rildo. Letramento literário: teoria e prática. 2.ed., $2^{\mathrm{a}}$ reimpressão. São Paulo: Contexto, 2012.

CUNHA, Maria Zilda da. Naus frágeis e novos paradigmas em literatura e Educação. Perspectiva, Florianópolis: UFSC, v. 30, n. 3, setembro/dezembro de 2012.

BASEIO, Maria Auxiliadora Fontana. Por uma aliança entre literatura e Educação. FronteiraZ - Revista do Programa de Estudos Pós-Graduados em Literatura e Crítica Literária, São Paulo, n. 14, 2015.

DIAS, Ana Crelia. Literatura e educação literária: quando a literatura faz sentido(s). Cerrados: Revista do Programa de Pós-Graduação em Literatura/UnB, Brasília/DF, v. 25, nº 42, 2016.

FILIPOUSKI, Ana Mariza Ribeiro. Para que ler literatura na escola? In. Teorias e fazeres na escola em mudança. Rio Grande do Sul: Editora UFRSG, 2005.

FREDERICO, Enid Yatsuda; OSAKABE, Haquira. Literatura. In Orientações Curriculares do Ensino Médio. Brasília: MEC/SEB/DPPEM, 2004. Disponível em: http://portal.mec.gov.br/seb/arquivos/pdf/03Literatura.pdf. Acesso em: 13 de maio de 2017.

GARCIA, Mirian Theyla Ribeiro. Silêncios e silenciados: o letramento literário de alunos surdos em turmas inclusivas no Ensino Médio e na Educação de Jovens e Adultos. Tese (doutorado em Literatura e Práticas Sociais). Brasília: Programa de Pós-graduação em Literatura. Universidade de Brasília (UnB), 2019.

KLEIMAN, Ângela Bustos. Letramento e suas implicações para o ensino de língua materna. Signo. Santa Cruz do Sul, v. 32, n. 53, dezembro de 2007.

MÜLLER, Janete Inês. Língua Portuguesa na educação escolar bilíngue de surdos. Tese (Doutorado em Educação). Universidade Federal do Rio Grande do Sul, 2016. 


\section{ITHarang REFLCTIONIS}

Revista Eletrônica de Graduação e Pós-Graduação em Educaçāo

NASCIMENTO, Cleideni Alves do. O lugar da leitura literária no século XXI. Muitas Vozes, v. 2, 2013.

PEREIRA, Danglei de Castro. Literatura e formação de leitores: o texto literário e a sala de aula. Revista de Letras Norte@mentos, v. 9, n. 18, Dossiê Letramento literário. Sinop: Universidade do Estado de Mato Grosso (UNEMAT), 2016.

PEREIRA, Marília Mesquita Guedes. A biblioterapia e leitura crítica para a formação da cidadania com os alunos do Instituto dos Cegos da Paraíba "Adalgisa Cunha". In: XIX Congresso Brasileiro de Biblioteconomia e Documentação, Rio Grande do Sul: Editora da PUC, 2000 .

PERRONE-MOISÉS, Leyla. Por amor à arte. Estudos Avançados. v. 19, n. 55. São Paulo: Universidade de São Paulo, setembro/dezembro de 2005.

ROJO, Roxane. Letramentos múltiplos, escola e inclusão social. São Paulo: Parábola Editorial, 2009.

SEGABINAZI, Daniela Maria; SILVA, Raquel Sousa da. O ensino de literatura continua em perigo... Revista Língua \& Literatura (Online), v. 17, n. 30, Número especial: Literatura, leitura e formação de leitores. Frederico Westphalen (RS): Universidade Regional Integrada do Alto Uruguai e das Missões (URI), dezembro de 2015. Disponível em: http://revistas.fw.uri.br/index.php/revistalinguaeliteratura/article/view/1967. Acesso em: 27 de janeiro de 2018.

TODOROV, Tzvetan. A literatura em perigo. Trad. Caio Meira. Rio de Janeiro: DIFEL, 2009.

ZAPPONE, Mirian Hisae Yaegashi; YAMAKAWA, Ibrahim Alisson Letramento dominante x vernacular e suas implicações para o ensino da literatura. Ponta Grossa: Muitas Vozes, v. 2, 2013.

ZILBERMAN, Regina; SILVA, Ezequiel Theodoro da. Literatura e Pedagogia. Ponto \& Contraponto. São Paulo/Campinas, Global/ALB, 2008. 